\title{
A cross-sectional study of current work ability after radical prostatectomy
}

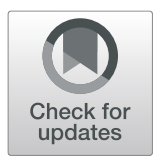

Alv A. Dahl ${ }^{1,2^{*}}$ (D, Bjørn Brennhovd ${ }^{3}$, Sophie D. Fosså ${ }^{1,2}$ and Karol Axcrona ${ }^{4}$

\begin{abstract}
Background: Work ability represents a person's subjective assessment of current ability to work compared to his lifetime best. Since many men with prostate cancer are retired, work ability represents a more relevant work measure than employment status. The primary aim was to examine the prevalence of men who had high versus moderate/poor current work ability compared to their lifetime best work ability at a mean of 3.0 years after robotassisted laparoscopic prostatectomy. The secondary aim was to study variables associated with moderate/poor work ability at survey.

Methods: This is a questionnaire-based study of men who had robot-assisted laparoscopic prostatectomy at Oslo University Hospital, Radiumhospitalet between January 2005 and August 2010. Among them 777 responded (79\%), 730 reported on current work ability, socio-demographic data, somatic and mental health, and typical adverse effects (the EPIC-26) after prostatectomy. High versus moderate/poor work ability was the primary outcome. Descriptive statistics and logistic regression analyses were applied.

Results: The mean age of the sample at survey was 65.5 years (SD 5.9). At survey $42 \%$ of the sample reported moderate/poor current work ability and 58\% reported high work ability. In multivariable analysis older age at survey, low basic education, comorbidity, poor self-rated health, presence of depression and low EPIC-26 hormonal domain score remained significantly associated with moderate/poor work ability.

Conclusions: Current work ability is a useful measure for the working capacity particularly of retired men. Sociodemographic, cancer-related, health, psychological and typical adverse effect variables were significantly associated with moderate/poor current work ability after robot-assisted laparoscopic prostatectomy, and several health and psychological variables are amenable to identification and treatment by health care providers.
\end{abstract}

Keywords: Work ability, EPIC-26, Prostatic neoplasm, Robot-assisted laparoscopic prostatectomy, Depression

\section{Background}

In Norway official retirement age is 67 years, but this age varies somewhat according to professions. The retirement age also varies in different countries, just as does the income granted after retirement. Many men are diagnosed and treated for prostate cancer (PCa) after retirement age. For them the official categories of employment such as paid work, unemployed, disability pension, or being on sick-leave, are not relevant as descriptors of their remaining working capacity. Many elderly PCa survivors use their considerable current work

\footnotetext{
* Correspondence: alvandreas@msn.com

${ }^{1}$ National Advisory Unit for Late Effects after Cancer Therapy, Oslo University Hospital, Radiumhospitalet, P. O. Box 4953, Nydalen, 0424 Oslo, Norway

${ }^{2}$ University of Oslo, Oslo, Norway

Full list of author information is available at the end of the article
}

ability for charity, family, hobbies, or social organizations making valuable, often unpaid contributions to society. Major treatment modalities for localized PCa are radical prostatectomy, radiotherapy, and active surveillance. Treatment is chosen according to risk group, age, and general health as well as preferences of the patients. Major side effects after radical prostatectomy are urinary incontinence, erectile dysfunction, reduced feelings of masculinity and self-esteem, and partner conflicts often affecting the patients' quality of life negatively [1]. At major urological centers radical prostatectomy is mainly performed as robot-assisted laparoscopic prostatectomy (RALP) as in this study.

A review of work-related self-report measures for cancer survivors, lists only one measure for ability to work: 
The Work Ability Index (WAI) [2]. The WAI was developed by a Finnish research group with a 24 items version [3-5]. Further research has demonstrated that the single item of current work ability score (WA) on a numeric scale from zero ('Currently not able to do work') to 10 ('Work ability as previous life-time best') from the WAI instrument showed strong correlation with the total score of the WAI short version and the psychometrics of rating WA in this way is well documented [6]. Therefore, we used a dichotomy of the current WA score as outcome variable of this study.

Studies of current WA among PCa survivors are few. Taskila et al. [7] reported that the mean current WA score of Finnish PCa survivors $(N=46)$ was 8.0 , but they had no controls. A Nordic study reported a mean of 7.6 for current WA score in PCa survivors $(N=112)$ versus 8.3 among cancer-free controls $(p<0,01)$ [8]. Dahl et al. [9] studied the current WA of Norwegian PCa survivors $(N=563)$ who were still active in the workforce less than 3 years after radical prostatectomy (RP). They dichotomized the current WA scores into poor/moderate $(0-7$ points), good (8-9 points), and excellent (10 points), and found that $24 \%$ of the survivors belonged to the moderate/poor WA category. They found that men with postRP radiotherapy or hormone treatment, urinary leakage, age above 65 years, or comorbidity significant more frequently belonged to the poor/moderate WA category compared to men of better WA categories [9].

These cross-sectional studies of current WA in men after RP are in need of expansion and replication since two of the studies have quite small samples. On this background, we analyzed data from a mailed questionnaire study of Norwegian men treated with RALP at our comprehensive cancer center. First, we identified the prevalence of $\mathrm{PCa}$ survivors with high versus moderate/ poor current WA. Second, we examined variables significantly associated with moderate/poor WA. Given the available evidence, we did not expect an association among WA and $\mathrm{PCa}$ characteristics and treatment variables.

\section{Methods}

\section{Sample and treatment}

Between January 2005 and August 2010, 988 men underwent RALP as primary treatment for PCa at Oslo University Hospital, Radiumhospitalet. By March 2011 six men had died, and a questionnaire was mailed to the remaining 982 patients, and 777 responded (79\% response rate). An attrition analysis between the respondents and the 205 non-respondents showed no significant differences on PCa-related and surgical variables except that the non-respondents were younger and had higher Clavien sum scores for operative complications [10]. Forty-seven responders were not included in our analysis due to incomplete data on current WA, leaving 730 men as our study sample.

Patients were operated with the same technique during all years (2005-2010), the Vattikutti technique, also described and published by our group [10,11]. The principles of this technique are basically used in the majority of centers operating RALP. The follow-up of patients has been consistent and equal for all patients in the study period and thereafter.

\section{Measures}

Current WA compared to the lifetime best WA was selfrated on a 10-point numerical rating as previously decribed [3-5]. We dichotomized the current WA scores into high WA (score 8-10) versus moderate/low WA (score 0-7).

\section{Anxiety and depression}

The Hospital Anxiety and Depression Scale (HADS) covers the last 7 days. Both the depression and the anxiety subscales have 7 items scored on a 4-point scale from 0 ('not present') to 3 ('considerable'), with subscale sum scores ranging from 0 to 21 . The cut-off scores for clinical anxiety and depression is a sum score $\geq 8[11,12]$. Cronbach's coefficient alpha was 0.85 for the anxiety and 0.79 for the depression subscale.

Neuroticism was self-rated on an abridged version of The Eysenck Personality Inventory (EPQ) for trait affects with six items each scored as present (1) or absent (0) [13]. The sum score ranged from 0 to 6 , and was dichotomized into high (sum score 3-6) and low neuroticism (sum score 0-2) according to Grav et al. [14]. Cronbach's alpha was 0.78 .

\section{Typical AEs}

The EPIC-26 is a self-report instrument for rating of typical AEs of the last 4 weeks covering the urinary, bowel, sexual, and hormonal domains after PCa treatment. While the urinary and sexual domains cover both function and bother, the bowel and hormonal ones cover only bother. The scores are converted from 0 (worst) to 100 (best) and group means are calculated $[15,16]$.

Among PCA-related variables pre-treatment risk groups were defined according to D'Amico et al. [17]. Biochemical PSA relapse, post-RP radiotherapy, and hormone treatment after RALP were self-reported, and defined as PCa treatment failure.

\section{Partnership status}

Men were either married or cohabiting or were not living with a partner. Non-employed status concerned men who were without paid work or pensioned. Low level of education was defined as $\leq 12$ school years 
completed versus high level ( $>12$ years). Comorbidity was based on self-report of stroke, diabetes, chronic obstructive lung diseases, liver disease, arthrosis, rheumatic diseases (all 1 point), and kidney disease (2 points) based on illness points according to Charlson et al. [18].

\section{Statistical analysis}

Descriptive statistics were performed with chi-square tests for categorical variables and independent sample t-tests for continuous variables, but with MannWhitney U-tests in case of skewed distributions. Onesample t-tests were used to compare the current WA mean score of our sample with that of other published samples.

To find the $p$-value adjusted for age, we used multivariate logistic analyses for categorical data, and multilinear linear analyses for continuous data. These statistical procedures were performed for each of the age-relevant independent variables with Low/moderate WA versus High WA (reference) as dependent variable.

Univariate and multivariable logistic regression analyses with relevant independent variables and moderate/low WA as outcome variable and high WA as reference were performed. The strength of associations was described by odds ratios (ORs) with 95\% confidence intervals $(95 \% \mathrm{CI})$. The level of significance was set at $p<0.05$, and all tests were two-sided. Data analyses were performed with IBM SPSS version 25.0 for PC (IBM, Armonk, NY).

\section{Results}

\section{Characteristics of the total sample}

The mean age of the sample at surgery was 62.5 years (SD 5.7). Of the total sample $23 \%$ belonged to the low risk, $41 \%$ to the intermediate, and $36 \%$ to the high risk group, and positive margins were observed in $28 \%$. Only nerve-sparing was significantly less frequent in the moderate/poor compared to the high WA group (Table 1).

The mean age of the sample at survey was 65.5 years (SD 5.9). At survey $42.3 \%$ (95\%CI 38.7-45.9\%) of the sample reported moderate/poor current WA and 57.7\% (95\%CI 54.1-61.3\%) reported high WA.

Of the sample $21 \%$ had experienced treatment failure at the survey which took place at a mean of 3.0 years (SD 1.4) after surgery (Table 2).

Table 1 Cancer-related data of the work ability groups at surgery

\begin{tabular}{|c|c|c|c|c|}
\hline Variables & Moderate/poor work ability $(N=309)$ & High work ability $(N=421)$ & $p$-value & Total sample $(N=730)$ \\
\hline Age at surgery, mean (SD) & $63.5(5.6)$ & $61.8(5.7)$ & $<0.001$ & $62.5(5.7)$ \\
\hline Clinical stage N (\%) & & & 0.74 & \\
\hline $\mathrm{T} 1-\mathrm{T} 2 \mathrm{a}$ & $198(64)$ & $281(67)$ & & $479(66)$ \\
\hline $\mathrm{T} 2 \mathrm{~b}$ & $40(13)$ & $49(11)$ & & $89(12)$ \\
\hline T3 & $71(23)$ & $91(22)$ & & $162(22)$ \\
\hline Gleason scores, N (\%) & & & 0.31 & \\
\hline 6 & $112(36)$ & $175(42)$ & & $287(39)$ \\
\hline 7 & $152(49)$ & $185(44)$ & & $337(46)$ \\
\hline $8-10$ & $45(15)$ & $61(14)$ & & $106(15)$ \\
\hline PSA. mean (SD) & $13.5(15.5)$ & $12.3(17.5)$ & 0.32 & $12.8(16.7)$ \\
\hline D'Amico risk categories, N (\%) & & & 0.16 & \\
\hline Low & $61(20)$ & $103(24)$ & & $164(23)$ \\
\hline Intermediate & $125(40)$ & $176(42)$ & & $301(41)$ \\
\hline High & $123(40)$ & $142(34)$ & & $265(36)$ \\
\hline Positive surgical margins, $N(\%)$ & $95(31)$ & $1 \mid 12(27)$ & 0.22 & $207(28)$ \\
\hline Nerve sparing, N (\%) & & & $<0.001$ & \\
\hline Bilateral & $61(20)$ & $126(30)$ & & $187(26)$ \\
\hline Unilateral & $133(43)$ & $195(46)$ & & $328(45)$ \\
\hline None & $115(37)$ & $100(24)$ & & $216(29)$ \\
\hline Patological stage, N (\%) & & & 0.24 & \\
\hline pT2a - pT2c & $145(47)$ & $216(51)$ & & $361(49)$ \\
\hline рT3a - pT3b & $164(53)$ & 205 (49) & & $369(51)$ \\
\hline
\end{tabular}


Table 2 Demographic, and health findings of the work ability groups at survey

\begin{tabular}{|c|c|c|c|c|}
\hline Variables & Moderate/poor work ability $(N=309)$ & High work ability $(N=421)$ & $p$-value & Total Sample $(N=730)$ \\
\hline Age at survey, mean (SD) & $66.4(5.8)$ & $64.8(5.8)$ & $<0.001$ & $65.5(5.9)$ \\
\hline Time RALP-survey (years), mean (SD) & $3.0(1.4)$ & $3.0(1.5)$ & 0.73 & $3.0(1.4)$ \\
\hline Treatment failure, N (\%) & $74(24)$ & $80(19)$ & 0.11 & $154(21)$ \\
\hline Basic education, $N(\%)$ & & & $<0.001$ & \\
\hline$>12$ years & $158(51)$ & $289(69)$ & & $447(61)$ \\
\hline$\leq 12$ years & $151(49)$ & $132(31)$ & & $283(39)$ \\
\hline Paired relationship, N (\%) & $276(89)$ & $392(93)$ & $0.04^{*}$ & $668(92)$ \\
\hline Employment status, N (\%) & & & $<0.001^{*}$ & \\
\hline Working full-time & $53(17)$ & $228(55)$ & & $281(38)$ \\
\hline Working part-time & $25(8)$ & $35(8)$ & & $60(8)$ \\
\hline Retired & $149(49)$ & $142(34)$ & & $291(40)$ \\
\hline Sick-leave/rehabilitation & $18(6)$ & $5(1)$ & & $23(3)$ \\
\hline Disability pension & $48(15)$ & $2(0)$ & & $50(8)$ \\
\hline Unspecified & $16(5)$ & $9(2)$ & & $25(3)$ \\
\hline Work ability, mean (SD) & $5.4(1.8)$ & $8.8(0.8)$ & $<0.001 *$ & $7.4(2.1)$ \\
\hline Comorbidity index, N (\%) & & & $<0.001^{*}$ & \\
\hline 0 point & $191(62)$ & $345(82)$ & & $536(73)$ \\
\hline 1 point & $85(28)$ & $60(14)$ & & $145(20)$ \\
\hline$\geq 2$ points & $33(10)$ & $16(4)$ & & $49(7)$ \\
\hline Poor self-rated health, N (\%) & $70(23)$ & $14(3)$ & $<0.001 *$ & $84(12)$ \\
\hline High neuroticism, N (\%)\# & $113(37)$ & $51(12)$ & $<0.001^{*}$ & $164(23)$ \\
\hline Clinical anxiety, N (\%)\# & $43(14)$ & $18(4)$ & $<0.001 *$ & $61(8)$ \\
\hline Clinical depression, N (\%)\# & $42(14)$ & $8(2)$ & $<0.001 *$ & $50(7)$ \\
\hline
\end{tabular}

${ }^{*}$ Adjusted for age at survey \#High neuroticism $=$ EPQ Neuroticism score $\geq 3$; Clinical anxiety $=$ HADS Anxiety sum $\geq 8$; Clinical depression $=$ HADS Depression sum $\geq 8$,

\section{Comparisons of the moderate/poor and the high WA groups at survey}

At survey the moderate/poor WA group had a significantly lower proportion in paired relationships, a lower proportion was still working full-time, and a higher proportion was retired compared to the high WA group. The poor/moderate WA group also had higher rates of comorbidity, poor self-rated health, high neuroticism, and men with anxiety or depression (Table 2).

The moderate/poor WA group had poorer mean function and bother score on all EPIC-26 issues compared to the high WA group (Table 3).

\section{Univariate and multivariable analyses}

The univariate analyses (not adjusted for age at survey like in Table 3) with moderate/poor WA as dependent variables mostly confirmed the significant betweengroup differences reported in Tables 3 and 4. Older age at survey, low basic education, comorbidity, poor selfrated health, high neuroticism, presence of depression and low EPIC-26 hormonal domain score remained significantly associated moderate/poor WA in the multivariable analysis (Table 4 ).

\section{Discussion}

Summary of main findings

In our sample of Norwegian men treated with RALP at a mean of 3 years earlier and with mean age of 65.5 years, $42 \%$ reported moderate/poor current WA and $58 \%$ reported high WA compared to their lifetime best. Our hypothesis was supported since only nerve-sparing among the PCa-related variables was associated with moderate/poor WA, while several demographic, health, psychological, and AEs variables showed such associations in bivariate analyses. Such variables also remained significant in the multivariable analyses.

\section{The usefulness of the WA measure}

Current WA compared to the lifetime best is a subjective concept rated by the patients, and thereby could be considered as a patient-reported outcome measure (PROM). WA is often divided into three components: physical, mental, and social, and in modern work life 
Table 3 EPIC-26 mean and standard deviation (SD) adverse effect findings of the work ability groups at survey

\begin{tabular}{|c|c|c|c|c|}
\hline Variables & Moderate/poor work ability $(N=309)$ & High work ability $(N=421)$ & $p$-value & Total sample $(n=730)$ \\
\hline Urinary domain, mean (SD) & $70.3(24.0)$ & $80.1(21.1)$ & $<0.001^{*}$ & $76.1(22.9)$ \\
\hline Incontinence subscale & $65.2(28.4)$ & $74.5(26.7)$ & $<0.001^{*}$ & $70.5(27.8)$ \\
\hline Irritation/obstruction subscale & $78.0(26.8)$ & $86.1(21.9)$ & $<0.001^{*}$ & $82.7(24.4)$ \\
\hline Overall urinary problem & $68.4(29.8)$ & $79.8(27.3)$ & $<0.001^{*}$ & $76.6(22.0)$ \\
\hline Bowel domain, mean (SD) & $86.1(20.5)$ & $93.0(15.0)$ & $<0.001^{*}$ & $90.1(17.8)$ \\
\hline Overall bowel problem & $87.9(22.1)$ & 94.2. (15.2) & $<0.001^{*}$ & $89.2(20.5)$ \\
\hline Sexual domain, mean (SD) & $26.6(25.8)$ & $35.5(28.3)$ & $0.001 * \#$ & $30.8(27.7)$ \\
\hline Erection ability & $17.6(26.7)$ & $25.0(29.8)$ & $0.011 * \#$ & $21.8(28.8)$ \\
\hline Difficulty with orgasm & $32.2(32.3)$ & $42.5(33.0)$ & $0.002 * \#$ & $38.1(33.1)$ \\
\hline Firmness of erections & $34.4(39.4)$ & $45.9(40.8)$ & $0.004 * \#$ & $41.0(40.6)$ \\
\hline Reliability of erections & $25.6(37.9)$ & $33.7(40.4)$ & $0.06^{*} \#$ & $30.3(39.6)$ \\
\hline Sexual function & $18.9(26.1)$ & $27.4(29.6)$ & $0.001 * \#$ & $23.8(28.5)$ \\
\hline Overall sexual problem & $30.7(31.4)$ & $38.4(33.2)$ & $0.002 * \#$ & $35.2(32.1)$ \\
\hline Hormonal domain; mean (SD) & $74.2(24.7)$ & $90.7(16.6)$ & $<0.001 *$ & $83.8(21.9)$ \\
\hline Hot flashes & $89.8(23.4)$ & $95.9(15.1)$ & $<0.001^{*}$ & $93.6(19.0)$ \\
\hline Breast problems & $93.8(18.4)$ & $98.2(9.3)$ & $<0.001^{*}$ & $96.4(13.9)$ \\
\hline Depression & $68.0(31.7)$ & $88.4(22.1)$ & $<0.001^{*}$ & $81.1(27.6)$ \\
\hline Lack of energy & $59.1(34.0)$ & $86.4(22.6)$ & $<0.001 * \#$ & $76.3(30.3)$ \\
\hline Weight change & $79.9(28.9)$ & $92.8(18.4)$ & $<0.001 *$ & $88.8(23.4)$ \\
\hline
\end{tabular}

*Adjusted for age at survey; \# Mann-Whitney U-test

Table 4 Univariate and multivariable logistic regression analyses of independent variables in relation to moderate/poor work ability (high as reference) as dependent variable

\begin{tabular}{|c|c|c|c|c|c|c|}
\hline \multirow[t]{2}{*}{ Variables } & \multicolumn{3}{|c|}{ Univariate analyses } & \multicolumn{3}{|c|}{ Multivariable analysis } \\
\hline & OR & $95 \% \mathrm{Cl}$ & $p$-value & OR & $95 \% \mathrm{Cl}$ & $p$-value \\
\hline Nerve-sparing & & & $<0.001$ & & & 0.06 \\
\hline Bilateral (reference) & 1.00 & - & - & 1.00 & - & - \\
\hline Unilateral & 2.38 & $1.58-3.27$ & $<0.001$ & 1.68 & $1.02-2.76$ & 0.04 \\
\hline None & 1.41 & $0.97-2.05$ & 0.08 & 1.09 & $0.69-1.72$ & 0.71 \\
\hline Age at survey & 1.06 & $1.03-1.08$ & $<0.001$ & 1.08 & $1.04-1.12$ & $<0.001$ \\
\hline Low basic education & 2.09 & $1.55-2.84$ & $<0.001$ & 1.84 & $1.29-2.64$ & 0.001 \\
\hline Non-paired relationship & 1.62 & $0.96-2.02$ & 0.07 & - & - & - \\
\hline Comorbidity & & & $<0.001$ & & & $<0.001$ \\
\hline 0 point (reference) & 1.00 & - & - & 1.00 & - & - \\
\hline 1 point & 2.56 & $1.76-3.72$ & $<0.001$ & 2.39 & $1.54-3.62$ & $<0.001$ \\
\hline$\geq 2$ points & 3.73 & $2.00-6.94$ & $<0.001$ & 3.05 & $1.46-6.35$ & 0.003 \\
\hline Poor self-rated health & 8.47 & $4.67-15.37$ & $<0.001$ & 5.66 & $2.76-11.60$ & $<0.001$ \\
\hline High neuroticisma & 4.18 & $2.88-6.07$ & $<0.001$ & 1.70 & $1.01-2.85$ & 0.045 \\
\hline Clinical anxiety ${ }^{a}$ & 3.62 & $2.04-6.71$ & $<0.001$ & 1.62 & $0.73-3.60$ & 0.23 \\
\hline Clinical depression ${ }^{a}$ & 8.12 & $3.75-17.57$ & $<0.001$ & 4.37 & $1.60-11.97$ & 0.004 \\
\hline Urinary domain & 0.98 & $0.97-0.99$ & $<0.001$ & 0.99 & $0.98-1.00$ & 0.09 \\
\hline Bowel domain & 0.98 & $0.97-0.99$ & $<0.001$ & 1.00 & $0.99-1.01$ & 0.96 \\
\hline Sexual domain & 0.99 & $0.98-0.99$ & $<0.001$ & 1.00 & $1.00-1.01$ & 0.51 \\
\hline Hormonal domain & 0.96 & $0.95-0.97$ & $<0.001$ & 0.98 & $0.97-0.99$ & $<0.001$ \\
\hline
\end{tabular}

${ }^{\mathrm{a}}$ High neuroticism $=$ EPQ Neuroticism score $\geq 3$; Clinical anxiety $=$ HADS Anxiety sum $\geq 8$; Clinical depression $=$ HADS Depression sum $\geq 8$ 
there has been a change of focus from the physical to social aspect [19]. We could speculate on when in men's life is their WA at "the lifetime best"? Physically the answer is young adult life, but with increased emphasis on the mental and social aspects "lifetime best" could occur in midlife due to training and experience. Our main point here is that the comparison between current WA and "lifetime best" do not necessarily imply a long-time span.

From Table 2 we see that $38 \%$ of our sample still are working full-time, while $40 \%$ are retired, so employment status does do not correlate highly with current WA in our sample. In contrast, current WA in retired men is used for many purposes both private, in the family, and in society. Rather than ignoring the WA of retired men, the WA measure shows the considerable work resources in this elderly group of men treated with RALP. We found that the fulltime workers have a much higher level of current WA than those who are in part-time employment or retired. Such a finding is not unexpected, but it does raise the question of whether the $\mathrm{PCa}$ cancer survivors' current work ability is enhanced by those continuing full-time work or whether their ability to engage in full-time work is influenced by the current WA. The general attitude of the Norwegian government is that persons who have reasonable WA should stay in their jobs as long as possible., and the GPs following these men should consider tehri optimal current WA.

Psychometric objections have been made for measuring current WA with only one item, but high correlation with the full WA score based on 24 items has been demonstrated [6]. A major objection to the current WA concept is the lack of population-based reference data both continuous and categorical. The validity of the findings if the Finnish Health 2000 Survey are doubtful in relation to recent studies from other countries [19].

\section{Comparisons with previous WA findings in men with PCa} In our sample of PCa survivors, the current WA mean score was 7.4 (SD 2.1) (Table 2). A Finnish sample with 46 survivors had a mean of 8.0, and a Nordic study with 112 survivors reported a mean of 7.6 for current WA. These mean scores were significantly higher than the mean current WA score of our study (one sample t-test $p<0.01)$.

The Dahl et al. study [8] included only men who were still active in the workforce after RP, so their high mean current WA score of 8.6 (SD 0.5) should be interpreted according to this premise. Being still in the workforce is also the explanation that their sample had $76 \%$ of men with high current WA in contrast to $58 \%$ in our sample including all sorts of work statuses $(p<0.001)$.

\section{New findings}

Not surprisingly, both the Finnish [7] and the Norwegian [9] studies found that both older age and comorbidity was significantly associated with reduced current WA score. In addition, the Finnish study found low education, and the Norwegian post-operative urinary leakage also were significantly associated with reduced current WA. Our study supported these findings, but in addition, we found that all domains of typical AEs after RALP were significantly associated with moderate/poor WA in bivariate analyses. Interestingly, of the four EPIC-26 domains scores (urinary, bowel, sexual, and hormonal) entered into the multivariable analysis, only the hormonal domain score remained significantly associated with moderate/poor WA. This could be associated with hormone treatment due to treatment failure, but also be due to depression in general since lack of energy is a central symptom of the depressive syndrome.

\section{Clinical implications}

We found that moderate/poor current WA was associated with several variables that should be amenable to diagnosis and treatment by health care providers, eventually improving current WA. Such variables were comorbidity, anxiety, and depression.

\section{Strengths and limitations}

Strengths of our study are the considerable sample size of men treated with RALP for PCa; an attrition analysis supporting the external validity of our findings; and use of established instruments with good psychometric properties. One limitation of the study is the crosssectional design, and that we thereby lack pre-treatment data of current WA. Prospective studies of current WA in men treated for PCa are needed in order to understand its influence on later WA. Reference data on current WA in older men is also needed. Another limitation was that the patients provided self-report data of the comorbidities rather than collecting such data from their medical records and their general practitioners.

\section{Conclusions}

Current WA is a useful measure for the working capacity of retired men. In our sample, $42 \%$ of the PCa survivors reported moderate/poor current WA and 58\% reported high WA, while $38 \%$ were in full-time and $8 \%$ in part-time work. In multivariable analysis older age, low basic education, comorbidity, poor self-rated health, high neuroticism, increased level of depression, and lower EPIC-26 domain score. Several of these variables are amenable to identification and treatment by health care providers. 


\section{Abbreviations}

Cl: Confidence Interval; EPIC-26: The Expanded Prostate Cancer Composite26; HADS: The Hospital Anxiety and Depression Scale; PCa: Prostate Cancer; PSA: Prostate Specific Antigen; RALP: Robot-Assisted Laparoscopic Prostatectomy; RP: Radical Prostatectomy; SD: Standard Deviation; WA: Work Ability; WAl: The Work Ability Index

\section{Acknowledgements}

None.

\section{Authors' contributions}

AAD contributed substantially to conception design, analysis, and interpretation of data, and to drafting of the manuscript. BB contributed substantially in conception, design, data acquision, and in the interpretation of the data, and in drafting the manuscript. SDF contributed substantially in conception, design, the interpretation of the data, and in drafting the manuscript. KA has made substantial contributions to conception and design, data acquision, data interpretation, and in drafting the manuscript. All authors read and approved the final version of the manuscript being submitted and agreed to be accountable for all parts of the research work.

\section{Funding}

No external source of funding.

\section{Availability of data and materials}

According to Norwegian data legislation, the data of this study cannot be made generally available. Requests may be made to the first author.

\section{Ethics approval and consent to participate}

The study was approved by the Regional Committee for Medical and Health Science Research of South-East Norway (REK no 2010/1511). All participants gave written informed consent.

\section{Consent for publication}

Not applicable.

\section{Competing interests}

The authors declare that they have no competing interests.

\section{Author details}

${ }^{1}$ National Advisory Unit for Late Effects after Cancer Therapy, Oslo University Hospital, Radiumhospitalet, P. O. Box 4953, Nydalen, 0424 Oslo, Norway. ${ }^{2}$ University of Oslo, Oslo, Norway. ${ }^{3}$ Department of Urology, Oslo University Hospital, Radiumhospitalet, Oslo, Norway. ${ }^{4}$ Department of Urology, Akershus University Hospital, Lørenskog, Norway.

Received: 27 February 2019 Accepted: 23 January 2020

Published online: 31 January 2020

\section{References}

1. Dahl AA, Nilsson R, Axcrona K, Fosså SD. Addressing erectile dysfunction in prostate cancer survivors after radical prostatectomy. Exp Rev Qual Life Cancer Care. 2016;1(5):403-20. https://doi.org/10.1080/23809000.2016. 1236660.

2. Ladehoff N, Sturm K, Mehnert A. Work-related self-report measures and assessment tools in cancer survivorship: a systematic literature review. Disabil rehab 2013; 35(2):100-112. DOl: https://doi.org/10.3109/09638288. 2012.688921.

3. Tuomi K, Ilmarinen J, Jakhola A, Katajarine I, Tulkki a. work ability index. 2nd edition. Helsinki: Finnish Institute of Occupational Health; 2006.

4. IImarinen J. Work ability - a comprehensive concept for occupational health research and prevention. J Work Environ Health. 2009;35(1):1-5.

5. Ahlstrom L, Grimsby-Ekman A, Hagberg M, Delive L. The work ability index and single-item question: associations with sick leave, symptoms, and health - a prospective study of women on long-term sick leave. Scand J Work Environ Health. 2010;36(5):404-12.

6. Taskila T, Martikainen R, Hietanen P, Lindbohm ML. Comparative study of work ability between cancer survivors and their referents. Eur J Cancer. 2007:43(5):914-20.

7. Lindbohm ML, Taskila T, Kuosma E, Hietanen P, Carlsen K, Gudbergsson S, et al. Work ability of survivors of breast, prostate, and testicular cancer in
Nordic countries: a NONOCWO study. J Cancer Surviv. 2012;6(1):72-81. https://doi.org/10.1007/s11764-011-0200-z.

8. Dahl S, Cvancarova M, Dahl AA, Fosså SD. Work ability in prostate cancer sursurvivors after radical prostatectomy. Scand J Urol. 2016;50(2):116-22. https://doi.org/10.3109/21681805.2015.1100674.

9. Brennhovd B, Axcrona K, Fosså SD, Giercksky K-E, Vlatkovic L, Dahl AA. Robot- assisted radical prostatectomy of clinical high-risk patients with prostate cancer: a controlled study of operative and short-term postoperative events. Scand J Urol. 2013;47(6):449-55. https://doi.org/10. 3109/21681805.2013.780257.

10. Axcrona K, Vlatkovic L, Hovland J, Brennhovd B, Kongsgaard U, Giercksky KE. Robot-assisted laparoscopic prostatectomy in a 68-year-old patient with previous heart transplantation and pelvic irradiation. J Robot Surg. 2012;6(1): 81-3. https://doi.org/10.1007/s11701-011-0270-y.

11. Bjelland I, Dahl AA, Tangen T, Neckelmann D. The validity of the hospital anxiety and depression scale. J Psychosom Res. 2002;52(2):69-77.

12. Mykletun A, Stordal E, Dahl AA. Hospital anxiety and depression (HAD) scale: factor structure, item analyses and internal consistency in a large population. Br J Psychiatry. 2001;179(2):540-4.

13. Grov EK, Fosså SD, Bremnes RM, Dahl O, Klepp O, Wist E, et al. The personality trait of neuroticism is strongly associated with long-term morbidity in testicular cancer survivors. Acta Oncol. 2009;48(6):842-9. https://doi.org/10.1080/02841860902795232.

14. Grav S, Stordal E, Romild UK, Hellzen O. The relationship between neuroticism, extraversion, and depression in the HUNT study: in relation to age and gender. Issues Ment Health Nurs. 2012;33(11):777-85. https://doi. org/10.3109/01612840.2012.713082.

15. Szymanski KM, Wei JT, Dunn RL, Sanda MG. Development and validation of an abbreviated version of the expanded prostate Cancer index composite instrument for measuring health-related quality of life among prostate cancer survivors. Urology. 2010;76(5):1245-50. https://doi.org/10.1016/j. urology.100.01.027.

16. Axcrona K, Nilsson R, Brennhovd B, Sørebo $\varnothing$, Fosså SD, Dahl AA. Psychometric properties of the expanded prostate Cancer index composite - 26 instrument in a cohort of radical prostatectomy patients: theoretical and practical examinations. BMC Urol. 2017;17(1):111. https://doi.org/10. 1186/s12894-017-0302-7.

17. D'Amico AV, Whittington R, Malkowicz SB, Schultz D, Blank K, Broderick GA, et al. Biochemical outcome after radical prostatectomy, external beam radiation therapy, or interstitial radiation therapy for clinically localized prostate cancer. JAMA. 1998;280(11):969-74.

18. Charlson ME, Pompei $P$, Ales K, MacKensie CR. A new method of classifying prognostic comorbidity in longitudinal studies: development and validation. J Chron Dis. 1987;40(5):373-83.

19. Gould R, Ilmarinen J, Järvisalo J, Koskinen S, editors. Dimensions of work ability. Helsinki: Finnish Center for Pensions; 2008. https://www.etk.fi/en/ julkaisu/dimensions-of-work-ability-2/. Accessed 04 Sept 2019

\section{Publisher's Note}

Springer Nature remains neutral with regard to jurisdictional claims in published maps and institutional affiliations.
Ready to submit your research? Choose BMC and benefit from:

- fast, convenient online submission

- thorough peer review by experienced researchers in your field

- rapid publication on acceptance

- support for research data, including large and complex data types

- gold Open Access which fosters wider collaboration and increased citations

- maximum visibility for your research: over $100 \mathrm{M}$ website views per year

At $\mathrm{BMC}$, research is always in progress.

Learn more biomedcentral.com/submissions 